\title{
Возможности современной
}

\section{медикаментозной коррекции метаболического синдрома:}

\section{роль желчных кислот}

\author{
Н. Б. Губергриц ${ }^{1}$, Н. В. Беляева ${ }^{1}$, Т. А. Можина ${ }^{2}$, Г. М. Аукашевич ${ }^{3}$, П. Г. Фоменко ${ }^{3}$ \\ ${ }^{1}$ Медицинский центр "Медикап", ОАесса, Украина \\ ${ }^{2} Ц$ ентр зАорового сердца, Харьков, Украина \\ ${ }^{3}$ Аонецкий национальный медицинский университет, Украина
}

Ключевые слова: урсодезоксихолевая кислота, метаболический синдром, неалкогольная жировая болезнь печени, гипергликемия, гиперхолестеринемия, атеросклероз сосудов

Метаболический синдром (МС) является одной из актуальных проблем практического здравоохранения во всем мире, учитывая его способность увеличивать распространенность кардиоваскулярной патологии и провоцировать рост сердечно-сосудистой смертности [18]. В настоящее время существует несколько дефиниций МС; как правило, термин МС используют для описания патологического состояния, сопровождающегося развитием инсулинорезистентности (ИР), гиперинсулинемии, дислипидемии, АГ и ожирения, нарушения толерантности к глюкозе $[9,18]$. Помимо «привычных» кардиологических проявлений МС выделяют гепатологическую составляющую этого синдрома - неалкогольную жировую болезнь печени (НАЖБП).

Среди факторов, способствующих развитию МС, особое внимание уделяют генетической предрасположенности, экологической составляющей, а также высококалорийной диете и низкому уровню физической активности $[2,16]$. Современные подходы к коррекции МС предполагают коррекцию указанных выше факторов риска, при недостаточной эффективности данных мер рекомендуют прием различных лекарственных средств. Одним из действенных современных направлений медикаментозного лечения МС является использование желчных кислот (ЖК).

\section{Свойства и функции Жк}

На протяжении последних нескольких лет опубликовано множество работ, констатирующих не только классические функции ЖК (участие в пищеварении и солюбилизации липофильных питательных веществ, лекарств в тонкой кишке), но и описывающих их сигнальные/эндокринные свойства $[20,25]$. Благодаря сигнальной активности ЖК и их дериваты принимают участие в различных метаболических реакциях.

\section{Биосинтез ЖК и их классические функиии}

Биосинтез ЖК представляет собой основной способ катаболизма холестерина (ХC) в организме человека. Преобразование ХС в ЖК представляет собой сложный ферментативный процесс, происходящий в гепатоцитах, единственных клетках, содержащих все необходимые ферменты для преобразования ядра молекулы ХС, удаления его боковых цепей, конъюгации с глицином $(\approx 75 \%)$ или таурином ( $\approx 25 \%)$. Трансформация ХС в ЖК происходит в ходе реакций гидроксилирования, насыщения двойной связи С5-С6, эпимеризации гидроксильной группы С3 и окислительного расщепления трех углеродов боковой цепи $[12,18]$. Все перечисленные реакции протекают в различных компартментах гепатоцита, в том числе в эндоплазматическом ретикулуме, митохондриях, цитоплазме и пероксисомах. В результате образуются две первичные ЖК (холевая и хенодезоксихолевая кислоты), впоследствии - вторичные ЖК (дезоксихолевая и литохолевая кислоты, урсодезоксихолевая кислота (УДХК)), выполняющие хорошо известные «классические» биохимические функции по перевариванию пищи.

Физико-химические свойства и сигнальная функиия Жк

ЖК обладают уникальными структурными и физико-химическими свойствами, позволяющими им проявлять сигнальную активность. ЖК содержат гидрофобный пергидроциклопентанофенантрен с гибкой боковой цепью, в которой расположены аминокислоты и полярные гидроксильные группы. Стероидное ядро с угловыми метильными группами в положении C-18 и C-19 обусловливает появление выпуклой гидрофобной $\beta$-поверхности, тогда как наличие полярных гидроксильных групп способствует формированию гидрофильной вогнутой 
$\alpha$-поверхности $[4,9]$. Таким образом, ЖК являются амфифильными молекулами, обладающими выраженной поверхностной активностью и способными самоассоциироваться в водных растворах, образовывать мицеллы, если их концентрация превышает определенный уровень, называемый критической мицеллярной концентрацией. Основным фактором, определяющим самоассоциацию ЖК, является их гидрофобность, которая зависит от химической структуры, в частности от количества и ориентации гидроксильных групп. ЖК, содержащие небольшое количество гидроксильных групп, обычно являются более гидрофобными, и наоборот [3]. Гидрофобные ЖК обладают более выраженными цитотоксическими свойствами (способность стимулировать образование активных форм кислорода, некроз и апоптоз) по сравнению с гидрофильными ЖК [9]. Самой гидрофобной ЖК, согласно данным хроматографического исследования, является литохолевая кислота, максимально гидрофильной - УДХК [15]. Будучи слабыми кислотами, в физиологических условиях ЖК пребывают в ионизированной форме, т. е. в виде солей желчи. Конъюгация этих соединений с глицином или таурином улучшает их физико-химические характеристики за счет снижения гидрофобных свойств и увеличения водорастворимости [9].

Специфическая структура ЖК, обусловленная амфифильными свойствами, позволяет выполнять им разнообразные специфические функции. Помимо солюбилизации жирных кислот, ХС и жирорастворимых витаминов, участия в их переваривании и транспорте, ЖК являются сигнальными молекулами, опосредуют различные метаболические процессы и сигнальные каскады $[4,6,9,14]$. Энтерогепатическая рециркуляция ЖК ассоциируется с активацией фарнезоидного рецептора X (FXR) - транскрипционного фактора, принимающего участие в регуляции биосинтеза и транспорта ЖК. Транскишечное выделение реабсорбированных ЖК способствует активации FXR в кишечнике и нормализации регуляции энтерогепатической рециркуляции этих амфифильных молекул. Благодаря перечисленным реакциям, протекающим в печени и кишечнике, гепатоциты защищены от перегрузки и накопления токсичных концентраций ЖК (так называемого гепатоцеллюлярного повреждения). Поддержание оптимального уровня ЖК в билиарном дереве и просвете кишечника необходимо для эмульгирования липидов пищи, взаимодействия с ядерными рецепторами, FXR, прегнан-X рецептором (PXR), рецептором витамина D (VDR) и конститутивным рецептором андростана (CAR), а также мембранным рецептором TGR5, что обуславливает появление системных сигнальных эффектов за пределами энтерогепатических тканей $[8,12]$.

\section{Участие ЖК в регуляции метаболизма глю-} козы

На протяжении последних нескольких лет опубликовано множество работ, описывающих участие ЖК в регуляции постпрандиального метаболизма глюкозы. Если первоначальные исследования утверждали, что ЖК и специфические синтетические агонисты FXR индуцируют экспрессию фермента, контролирующего скорость глюконеогенеза, - фосфоэнолпируваткарбоксикиназы (РЕРСК), что сопровождается увеличением уровня глюкозы в гепатоцитах человека и крыс, а также у мышей in vivo, то в более поздних работах получены совершенно другие результаты [9]. Установлено, что ЖК подавляют экспрессию генов глюконеогенеза PEPCK, глюкозо-6-фосфатазы и фруктозо-1,6-бис фосфатазы в условиях как in vivo, так и in vitro [9, 22]. Снижение экспрессии РЕРСК расценивают как один из возможных способов коррекции гипергликемии при сахарном диабете (СД) 2-го типа [9]. Рис. 1 демонстрирует способность ЖК влиять на метаболизм глюкозы посредством FXR и TGR5-сигнальных путей.

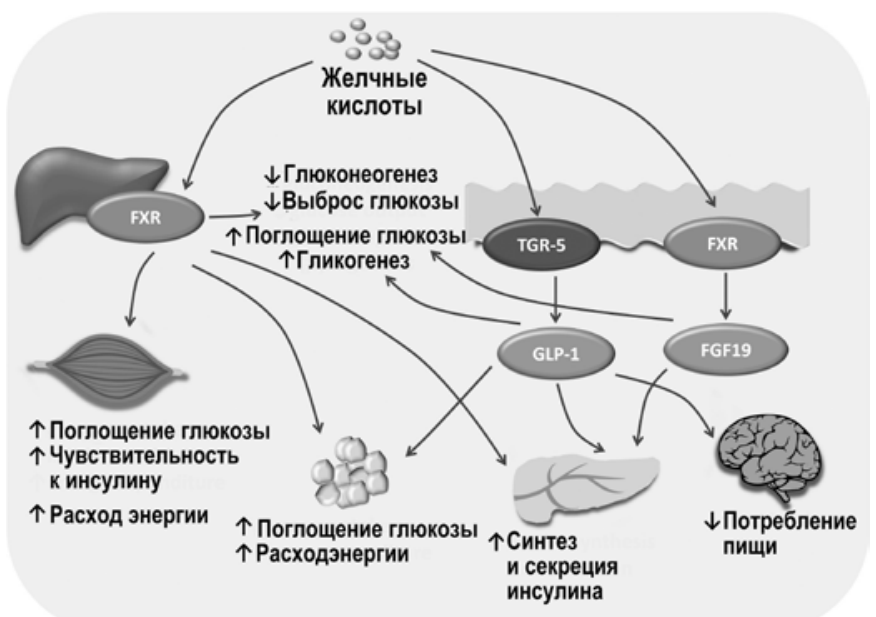

Рис. 1. Сигнальные пути метаболизма глюкозы, опосредованные ЖК (по М. Danic et al., 2018 [9]). Активация FXR и TGR5 поА возАействием ЖК привоАит к ингибированию глюконеогенеза и способствует синтезу гликогена в печени, глюкозо-опосредованному высвобождению инсулина в поджелудочной железе, увеличению расхода энергии, особенно в скелетной мускулатуре и коричневой жировой ткани. В головном мозге поА воздействием ЖК-TGR5-опосредованного сигнального пути появляется ощущение сытости.

Кроме того, активация FXR в печени приводит к повышению активности гликогенсинтазы и снижению уровня гликемии $[19,22]$. FXR-индуцированная активация транскрипции и секреции инсулина в $\beta$-клетках поджелудочной железы регулируется различными механизмами, включающими как геномные, так и негеномные эффекты. Геномные эффекты FXR-активации основаны на индукции глюкозозависимой транскрипции krueppel-подобного фактора 11 (KLF11), который, как доказано, является основным фактором транскрипции гена инсулина.

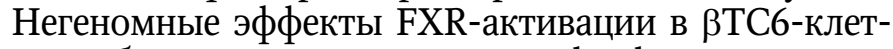
ках обеспечивают увеличение фосфорилирования Akt и транслокации транспортера глюкозы 2-го типа (GLUT2), входящего в состав мембранных белков, облегчающих транспорт глюкозы благодаря градиенту концентрации на плазменной мембране (рис. 2) [9]. Кроме того, активация FXR индуцирует экспрессию GLUT4 в печени, уровень которого у больных СД 1-го и 2-го типов снижен. 


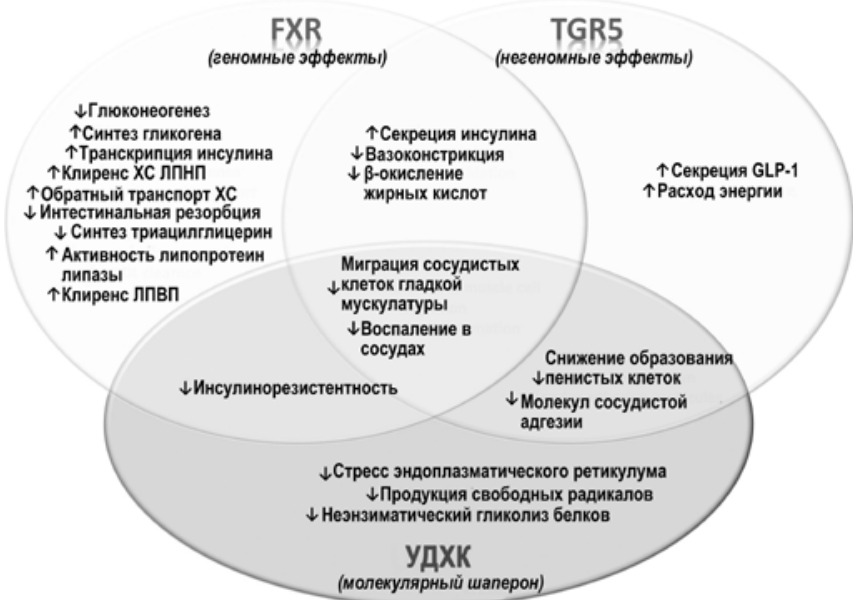

Рис. 2. Рецептор-зависимая и рецептор-независимая регуляция метаболических и сигнальных путей поА возАействием ЖК при метаболическом синдроме (по М. Danic et al., 2018 [9]). В^ияние ЖК-активированных рецепторов FXR и TGR5 на метаболизм глюкозы, мипиАов и энергии, атеросклероз-ассоциированные карАиоваскулярные события. FXR и TGR5 опосредуют значительное количество разнообразных и взаимосвязанных эффектов. С Аругой стороны, влияние УАХК не связано с непосредственной активацией указанных рецепторов ЖК, вместо этого УАХК оказывает различные физиологические/фармакологические воздействия, опосредованные ее специфическими структурными свойствами.

Есть данные, демонстрирующие способность ЖК влиять на гомеостаз глюкозы, не влияя на FXR [26]. Доказано, что активация мембранного рецептора TGR5 под действием ЖК сопровождается увеличением интестинальной секреции GLP-1 в энтероэндокринных L-клетках как в условиях in vitro, так и in vivo, что стимулирует высвобождение инсулина из $\beta$-клеток поджелудочной железы и уменьшение постпрандиальной гликемии [11].

Имеются доказательные данные, подтверждающие способность УДХК уменьшать гипергликемию и гиперинсулинемию, ИР и стеатоз у мышей линии KK-A(у), получающих рацион с высоким содержанием жира [27].

Способность УДХК влиять на метаболизм глюкозы зафиксирована в различных клинических исследованиях и подтверждена в недавно опубликованном метаанализе [23]. Метаанализ результатов семи клинических исследований зафиксировал достоверное снижение уровня гликемии натощак после терапии УДХК (взвешенная разность средних (ВРС) -3,30 мг/дл; 95\% доверительный интервал (ДИ) от $-6,36$ до -0,24; $\mathrm{p}=0,034$ [23]. Отмечено также значимое снижение концентрации гликозилированного гемоглобина (HbA1c) (BPC -0,41\% мг/дл; 95\% ДИ от $-0,81$ до $-0,01 ; \mathrm{p}=0,042)$ и уровня инсулина в плазме крови (ВРС - 1,50 мг/дл; 95\% ДИ от -2,81 до -0,19; $\mathrm{p}=0,025)$ и недостоверное влияние на значения HOMA-IR (BPC -0,20 мг/дл; 95\% ДИ от $-0,42$ до $0,01 ; \mathrm{p}=0,057)$ [23]. Результаты этого метаанализа доказали, что УДХК достоверно снижает концентрацию глюкозы в плазме крови натощак, уровень HbA1c и инсулина, что свидетельствует о положительном влиянии этой ЖК на гомеостаз глюкозы.
ЖК и атеросклеротические изменения сосудов

Помимо системного воздействия на уровень липидов в сыворотке крови, ЖК могут оказывать антиатеросклеротическое действие через FXR непосредственно на стенки артерий. Сосудистая стенка, как правило, не участвует в метаболизме ЖК, но установлено, что FXR экспрессируется в эндотелиальных и сосудистых клетках гладкой мускулатуры [19]. Активация FXR циркулирующими ЖК благоприятно влияет на тонус сосудов, подавляя действие мощного вазоконстрикторного пептида (эндотелина-1) и усиливая выработку вазодилатирующего вещества оксида азота (NO).

Установлено, что назначение УДХК (13-19 мг/кг 2 раза в сутки) на протяжении 6 недель пациентам с ишемической болезнью сердца сопровождалась эндотелийзависимой и NO-независимой вазодилатацией [24]. В условиях in vitro зафиксированы антиатерогенные свойства УДХК в модели диабетического атеросклероза в линии клеток Raw 264.7 и HUVEC посредством ингибирования неферментативного гликозилирования, окисления белков и липидов [7]. УДХК уменьшает стресс эндоплазматического ретикулума, улучшает функционирование сигнального пути в эндотелиальных клетках, тканях аорты у мышей, страдающих СД и нокаутированных по АроЕ, ингибирует продукцию реактивных форм кислорода с помощью индукции Nrf2 (основного транскрипционного фактора, стимулирующего транскрипцию и синтез антиоксидантных ферментов), а также ингибирует NF-кB и JNK-опосредованное воспаление эндотелия сосудов. УДХК угнетает формирование пенистых клеток за счет повышения экспрессии ABCA1 и ABCG1, подавляет макрофагобусловленный воспалительный ответ, значительно уменьшая выраженность атеросклероза [7]. Эти данные показывают, что УДХК, как широко используемый химический шаперон, может использоваться для профилактики или лечения диабетического атеросклероза. Скармливание УДХК (400-600 мг/кг/сутки) мышам линии АроЕ КО с поток-индуцированным атеросклерозом (за счет частичной перевязки левой коронарной артерии), которые содержались на высокожировой диете, уменьшало выраженность атеросклеротического поражения сосудов и ассоциировалось с ингибированием эндоплазматического стресса [7].

В клинических исследованиях получены подобные данные. В работе B. Ozel Coskun и соавт., назначавших УДХК (15 мг/кг в сутки на протяжении 6 месяцев) больным неалкогольным стеатогепатитом без сопутствующего СД, АГ, гиперлипидемии, зафиксировано достоверное снижение значений индекса НОМА с $3,4 \pm 1,89$ до 2,06 11,68 $(\mathrm{p}<0,001)$ [21]. Исследователи констатировали значимое уменьшение уровня апо А1 и индекса апо B/A1 с достоверным сокращением средних значений толщины комплекса интима-медиа (с $0,56 \pm 0,15$ до 0,47 $\pm 0,12 ; \mathrm{p}=0,001)$. Полученные данные авторы объяснили снижением ИР и повышением уровня липопротеина-апо А1 в сыворотке крови под влиянием УДХК. 


\section{YPCOHOCT}

\section{YPCOIEBOKCIXXUEBA KVICIOTA $300 \mathrm{MrN} 20$}

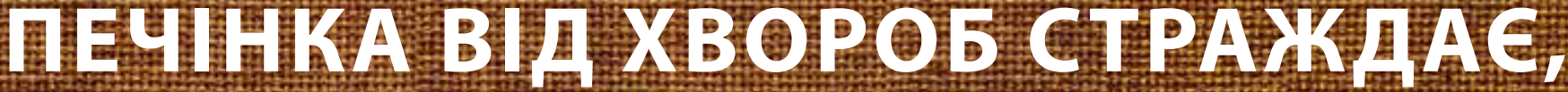 3 YPCOIOCIOM-POBKBIAAI}

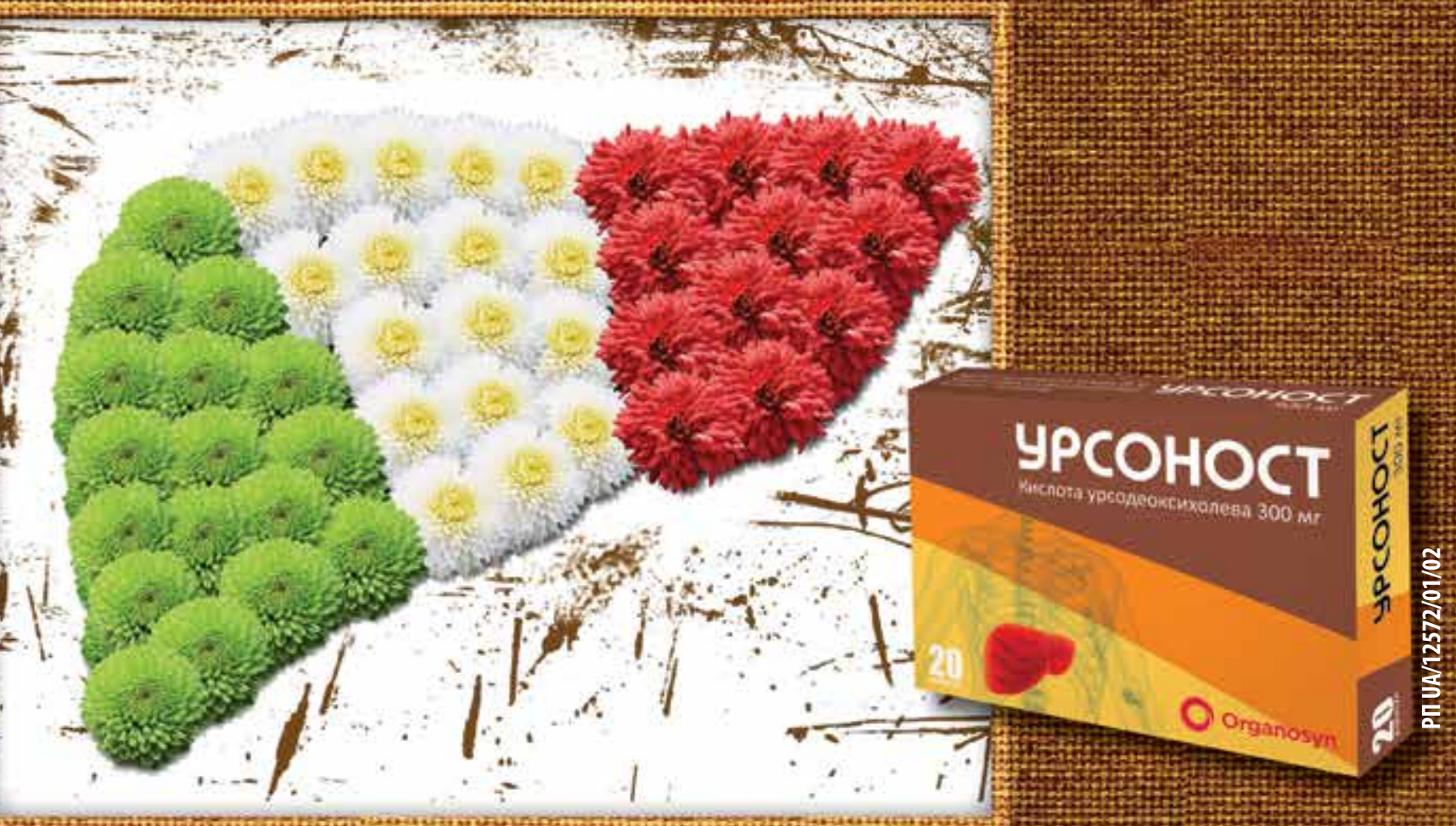

. РОЗЧИНЕННЯ РЕНТГЕН-НЕГАТИВНИХ ХОЛЕСТЕРИНОВИХ ЖОВЧНИХ КАМЕНІВ

Q АЛЯ ЗАПОБІГАННЯ У ТВОРЕННЮ ЖОВЧНИХ КАМЕНІВ У ПАLIEHTIB 3 ОЖИРІННЯМ, ЯКІ ПЛАНУЮТЬ ШВИДКО СКИНУТИ ВАГУ

2 СТАНИ, ПОВ'ЯЗАНІ 3 РЕФЛЮКСОМ ЖОВЧІ

- HЕАЛКОГОЛЬННА ТА АЛКОГОЛЬННА ХВОРОБИ ПЕЧІНКИ - БIЛIAРНИЙ СЛАДЖ 


\section{ЖК и НАЖБП}

НАЖБП, характеризующаяся избыточным накоплением триглицеридов в гепатоцитах, является одним из наиболее распространенных хронических заболеваний печени [5]. НАЖБП ассоциирована с некоторыми компонентами МС, в частности СД 2-го типа и ожирением [17], являясь, таким образом, важным фактором риска смертности вследствие как патологии печени, так и сердечно-сосудистых заболеваний $[10,17]$. В настоящее время НАЖБП рассматривается как гепатологическое проявление МС. ИР является одним из основополагающих факторов формирования НАЖБП и СД 2-го типа. Помимо ИР, прогрессированию НАЖБП способствуют окислительный стресс, гипоадипонектинемия и висцеральное ожирение [13]. Накопление триглицеридов в гепатоцитах является результатом липолиза вследствие ИР, воспаления, увеличения количества жировой ткани, нарушения митохондриального окисления жирных кислот или нарушения образования и экспорта липопротеинов низкой плотности [4].

Положительное влияние FXR и TGR5-опосредованной активации ЖК в целом ряде метаболических процессов, включая метаболизм глюкозы, триглицеридов, ХС и инсулиновый сигнальный путь, является основанием для применения препаратов, их содержащих, для коррекции гепатологических проявлений МС. По данным J. Нu, анализировавшего влияние раствора УДХК на содержание липидов в линии клеток LO2 со стеатозом, индуцированным введением олеиновой кислоты, УДХК подавляет активацию AKT, mTOR, CRTC2 и экспрессию nSREBP-1, тормозит развитие стеатоза, спровоцированного олеиновой кислотой, за счет регуляции трансдукции сигнала AKT/mTOR/SREBP-1 [14].

\section{Аитература:}

1. Пирогова И. Ю., Яковлева С. В., Неуймина Т. В. и Ар. Плейотропные эффекты урсодезоксихолевой кислоты при неалкогольной жировой болезни печени и метаболическом синароме. Consilium Medicum. 2019. No 21(8). C. 65-70.

2. Aguilar M., Bhuket T., Torres S., Liu B., Wong R. J. Prevalence of the metabolic syndrome in the United States, 2003-2012. JAMA. 2015. № 313. P. 1973-1974.

3. Ashby K., Navarro Almario E., Tong W., Borlak J., Mehta R. et al. Review article: therapeutic bile acids and the risks for hepatotoxicity. Aliment. Pharmacol. Ther. 2018. No 47. P. $1623-1638$.

4. Bellanti F., Villani R., Tamborra R., Blonda M., lannelli G. et al. Synergistic interaction of fatty acids and oxysterols impairs mitochondrial function and limits liver adaptation during nafld progression. Redox Biol. 2018. Vol. 15. P. 86-96.

5. Benedict M., Zhang $X$. Non-alcoholic fatty liver disease: an expanded review. World J. Hepatol. 2017. No 9. P. $715-732$.

6. Chávez-Talavera O., Tailleux A., Lefebvre P., Staels B. Bile acid control of metabolism and inflammation in obesity, type 2 diabetes, dyslipidemia, and
Согласно результатам клинического исследования, проведенного под руководством И. Пироговой, 24-недельный прием УДХК пациентами мужского пола, страдающими НАЖБП и $\mathrm{MC}(\mathrm{n}=70)$, сопровождался снижением уровня гликозилированного гемоглобина на $17 \%(\mathrm{p}<0,05)$, индекса HOMA на $15 \%(\mathrm{p}<0,04)$, уровня общего XС на $12 \%$ $(\mathrm{p}<0,05)$, триглицеридов на $21 \%(\mathrm{p}<0,05)$, липопротеинов низкой плотности на $21 \%(\mathrm{p}<0,05)$, увеличением содержания липопротеинов высокой плотности на 28\% ( $<0,05)$, уменьшением выраженности стеатоза печени $\left(\mathrm{dB} / \mathrm{m}^{2}\right)$ на $26 \%(\mathrm{p}<0,01)$ и снижением стадии фиброза печени по Metavir в $40 \%$ случаев [1].

\section{Заключение}

В настоящее время МС расценивается как полиморбидное состояние, предрасполагающие к возникновению сопутствующих заболеваний, в том числе атеросклероза и ишемической болезни сердца, СД и НАЖБП. Патогенетически обоснованным способом профилактики и коррекции MC и коморбидных патологий может быть применение ЖК, в частности УДХК (Урсоност, представляемый компанией Organosyn Life Sciences). Назначение УДХК (Урсоност) позволяет скорректировать разнообразные клинические проявления MC: нормализовать метаболизм глюкозы, снизить ИР, уменьшить атеросклеротическое поражения сосудов и выраженность стеатоза печени. Сигнальная функция такой вторичной ЖК, как УДХК (Урсоност), подтвержденная в экспериментальных, клинических исследованиях, позволяет противодействовать прогрессированию патологических процессов, развивающихся при MC.

nonalcoholic fatty liver disease. Gastroenterology. 2010. No 152. P. 1679-1694.e3.

7. Chung J., An S., Kang S., Kwon K. Ursodeoxycholic acid (UDCA) exerts anti-atherogenic effects by inhibiting RAGE signaling in diabetic atherosclerosis. PLoS One. 2016. No 11. e0147839.

8. Comeglio P., Morelli A., Adorini L., Maggi M., Vignozzi L. Beneficial effects of bile acid receptor agonists in pulmonary disease models. Expert Opin. Investig. Drugs. 2017. No 26. P. 1215-1228.

9. Đanić M, Stanimirov B, Pavlović N, Golocorbin-Kon S. et al. Pharmacological applications of bile acids and their derivatives in the treatment of metabolic syndrome. Front. Pharmacol. 2018. No 9. P. 1382.

10. Demir M., Lang S., Steffen H. M. Nonalcoholic fatty liver disease - current status and future directions. J. Dig. Dis. 2015. No 16. P. 541-557.

11. Duboc H., Tache Y., Hofmann A. F. The bile acid TGR5 membrane receptor: from basic research to clinical application. Dig. Liver Dis. 2014. Vol. 46, No 4. P. 302-312.

12. Gioiello A., Cerra B., Mostarda S., Guercini C., Pellicciari $\mathrm{R}$. et al. Bile acid derivatives as ligands of the farnesoid $\mathrm{x}$ receptor: molecular determinants for bile 
acid binding and receptor modulation. Curr. Top. Med. Chem. 2014. No 14. P. 2159-2174.

13. Gruben N., Shiri-Sverdlov R., Koonen D. P., Hofker M. H. Nonalcoholic fatty liver disease: a main driver of insulin resistance or a dangerous liaison? Biochem. Biophys. Acta. 2014. No 1842. P. 2329-2343.

14. Hu J., Hong W., Yao K. N., Zhu X. H., Chen Z. Y. et al. Ursodeoxycholic acid ameliorates hepatic lipid metabolism in LO2 cells by regulating the AKT/mTOR/SREBP-1 signaling pathway. World J. Gastroenterol. 2019. Vol. 25, No 12. P. 1492-1501.

15. Jia W., Xie G., Jia W. Bile acid-microbiota crosstalk in gastrointestinal inflammation and carcinogenesis. Nat. Rev. Gastroenterol. Hepatol. 2017. No 15. P. 111-128.

16. Kaur J. A comprehensive review on metabolic syndrome. Cardiol. Res. Pract. 2014. No 94. P. 3162.

17. Lam D., LeRoith D. The worldwide diabetes epidemic. Curr. Opin. Endocrinol. Diabetes Obes. 2012. No 19. P. 93-96.

18. McCracken E., Monaghan M., Sreenivasan S. Pathophysiology of the metabolic syndrome. Clin. Dermatol. 2018. No 36. P. 14-20.

19. Mencarelli A., Fiorucci S. FXR an emerging therapeutic target for the treatment of atherosclerosis. J. Cell. Mol. Med. 2010. No 14. P. 79-92.

20. Molinaro A., Wahlstrom A., Marschall H. Role of bile acids in metabolic control. Trends Endocrinol. Metab. 2018. No 29. P. 31-41.

21. Ozel Coskun B. D, Yucesoy M, Gursoy S. et al. Effects of ursodeoxycholic acid therapy on carotid intima media thickness, apolipoprotein A1, apolipoprotein B, and apolipoprotein $\mathrm{B} / \mathrm{A} 1$ ratio in nonalcoholic steatohepatitis. Eur. J. Gastroenterol Hepatol. 2015. Vol. 27, No 2. P. 142-149.

22. Renga B, Mencarelli A, Vavassori P, Brancaleone V, Fiorucci $S$. The bile acid sensor FXR regulates insulin transcription and secretion. Biochem. Biophys. Acta. No 1802, P. 363-372.

23. Sánchez-García A., Sahebkar A., Simental-Mendía M., Simental-Mendía L. E. Effect of ursodeoxycholic acid on glycemic markers: A systematic review and meta-analysis of clinical trials. Pharmacol. Res. 2018. No 135. P. 144-149.

24. Sinisalo J., Vanhanen H., Pajunen P., Vapaatalo H. et al. Ursodeoxycholic acid and endothelial-dependent, nitric oxide-independent vasodilatation of forearm resistance arteries in patients with coronary heart disease. Br. J. Clin. Pharmacol. 1999. Vol. 47, No 6. P. 661-665.

25. Shapiro H., Kolodziejczyk A., Halstuch D., Elinav E. Bile acids in glucose metabolism in health and disease. J. Exp. Med. 2018. No 215. P. 383-396.

26. Stanimirov B., Stankov K., Mikov M. Pleiotropic functions of bile acids mediated by the farnesoid $\mathrm{X}$ receptor. Acta Gastroenterol. Belg. 2012. No 75. P. 389-398.

27. Tsuchida T., Shiraishi M., Ohta T., Sakai K., Ishii S. Ursodeoxycholic acid improves insulin sensitivity and hepatic steatosis by inducing the excretion of hepatic lipids in high-fat diet-fed KK-Ay mice. Metabolism. 2012. Vol. 61, No 7. P. 944-953.

Под воздействием УАXK происходит активация FXR в печени, что обуславливает повышение активности гликогенсинтазы и снижение уровня гликемии. Аругой механизм, посреАством которого УАХК влияет на уровень гликемии, опосредован активацией мембранного рецептора TGR5 поА возАействием этой желчной кислоты, а также высвобождением инсулина из $\beta$-клеток поджелудочной железы и уменьшением постпрандиальной гликемии. При приеме УАХК снижается концентрация гликозилированного гемоглобина, инсулина в плазме крови, уменьшаются явления инсулинорезистентности. УАХК благотворно влияет на сосудистую стенку, уменьшая выраженность атеросклеротических поражений и нормализуя среАние значения толщины комплекса интима-медиа. УАХK улучшает метаболизм липиАов за счет регуляции активности сигнального пути AKT/mTOR, снижает синтез холестерина (XC), уменьшает фракционную скорость синтеза XС и фракционную скорость синтеза триглицеридов. Аоказано, что прием УАХК сопровожАается снижением уровня общего ХС и ХС липопротеинов низкой плотности. Нормализация метаболизма глюкозы, триглицериАов, ХС и инсулинового сигнального пути поА воздействием желчных кислот является основанием Аля применения УАХК Аля коррекции метаболического синдрома, а также его гепатологических проявлений - НАЖБП. 
УАК 616-008.9-085.272:612.357.15

doi: $10.33149 /$ vkp.2020.02.12

\section{UA Можливості сучасної медика- ментозної корекції метаболічного СИНАрОМу: РОАь ЖОВчних КИслот}

\author{
Н. Б. Губергриц ${ }^{1}$, Н. В. Бєляєва ${ }^{1}$, Т. А. Можина ${ }^{2}$, \\ Г. М. Аукашевич ${ }^{3}$, П. Г. Фоменко \\ ${ }^{1}$ Медичний центр "Медікап", Одеса, Україна \\ ${ }^{2}$ Центр зАорового серця, Харків, Україна \\ ${ }^{3}$ Аонецький національний меАичний університет, \\ Україна
}

Ключові слова: урсодезоксихолева кислота, метабомічний синаром, неалкогольна жирова хвороба печінки, гіперглікемія, гіперхолестеринемія, атеросклероз суАин

Після віАкриття методу синтезу урсодезоксихолевої кислоти (УАХК) і публікації доказів, що піАтверАжують їі зАатність зменшувати літогенні властивості жовчі, почалось активне клінічне застосування УАХК у всьому світі. Цей препарат крім Аоведеної холеретичної, мітолітичної, антиапоптичної дії володіє сигнальною активністю, що Аозволяє УАХК впливати на такі компоненти метаболічного синарому, як гіперглікемія, гіперхолестеринемія.

ПіА впливом УАХK відбувається активація FXR в печінці, що сприяє піАвищенню активності глікогенсинтази і зниженню рівня глікемії. Інший механізм, за Аопомогою якого УАХК впливає на рівень глікемії, опосередкований активацією мембранного рецептора TGR5 піА впливом цієї жовчної кислоти, а також вивільненням інсуліну з $\beta$-клітин підшлункової залози і зменшенням постпрандіальної глікемії. При прийомі УАХК знижується концентрація глікозильованого гемоглобіну, інсуліну в плазмі крові, зменшуються явища інсулінорезистентності. УАХК благотворно впливає на судинну стінку, зменшуючи виразність атеросклеротичних уражень і нормалізуючи середні значення товщини комплексу інтима-медіа. УАХK покращує метаболізм ліпіАів за рахунок регуляції активності сигнального шляху AKT/mTOR, знижує синтез холестерину (XC), зменшує фракційну швиАкість синтезу XС і фракційну швиАкість синтезу тригліцериАів. Аоведено, що прийом УАХК супроводжується зниженням рівня загального ХС і ХС ліпопротеїнів низької щільності. Нормалізація метаболізму глюкози, тригліцеридів, ХC і інсулінового сигнального шляху піА впливом жовчних кислот $є$ піАставою Аля застосу- вання УАХК Аля корекції метаболічного синАрому, а також его гепатологічних проявів - НАЖБП.

\section{EN Possibilities of modern drug correction of metabolic syndrome: the role of bile acids}

\author{
N. B. Gubergrits ${ }^{1}$, N. V. Byelyayeva ${ }^{1}$, T. L. Mozhyna ${ }^{2}$, \\ G. M. Lukashevich ${ }^{3}$, P. G. Fomenko ${ }^{3}$ \\ ${ }^{1}$ Medical Center "Medikap", Odessa, Ukraine \\ ${ }^{2}$ Healthy Heart Center, Kharkiv, Ukraine \\ ${ }^{3}$ Donetsk National Medical University, Ukraine
}

Key words: ursodeoxycholic acid, metabolic syndrome, non-alcoholic fatty liver disease, hyperglycemia, hypercholesterolemia, vascular atherosclerosis

After the discovery of the method of synthesis of ursodeoxycholic acid (UDCA) and the publication of evidence confirming its ability to reduce the lithogenic properties of bile, active clinical use of UDCA began around the world. This drug, in addition to the proven choleretic, cytoprotective, litholytic, anti-apoptotic effects, has a signaling activity that allows UDCA to influence metabolic syndrome components such as hyperglycemia, hypercholesterolemia.

Under the influence of UDCA, FXR is activated in the liver, which leads to an increase in the activity of glycogen synthase and decrease in the level of glycaemia. Another mechanism by which UDCA affects glycaemia is mediated by the activation of the TGR5 membrane receptor under the influence of this bile acid, as well as the release of insulin from pancreatic $\beta$-cells and decrease in postprandial glycaemia. When taking UDCA, the concentration of glycosylated hemoglobin, insulin in the blood plasma decreases the effects of insulin resistance decrease. UDCA has a beneficial effect on the vascular wall, reducing the severity of atherosclerotic lesions and normalizing the average thickness of the intima-media complex. UDCA improves lipid metabolism by regulating the activity of the AKT/ mTOR-signaling pathway, reduces the synthesis of cholesterol, and decreases the fractional rate of cholesterol synthesis and the fractional rate of triglyceride synthesis. It is proved that UDCA administration is accompanied by a drop in the level of total cholesterol and cholesterol of low-density lipoproteins. Normalization of the metabolism of glucose, triglycerides, cholesterol and the insulin-signaling pathway under the influence of bile acids is the basis for the use of UDCA for the correction of metabolic syndrome, as well as its hepatological manifestations - NAFLD. 